\title{
INCIDENCE OF CONSANGUINEOUS MARRIAGE IN RECENT METROPOLIS TOKYO ${ }^{1}$
}

\author{
Katumi TanaKa, * Kiyoshi Haraoka,** and Reiko Hayase* \\ *Department of Human Genetics, Tokyo Medical and Dental University, Tokyo \\ **Pediatric Clinic, Musashino Red-Cross Hospital, Tokyo
}

\begin{abstract}
Summary Information was obtained on consanguinity between parents of outpatients, born in 1960-1976, at the pediatric clinic in a hospital in Tokyo. Of 2,383 couples living in Metropolis Tokyo, 16 or $0.67 \%$ were first cousins, 8 or $0.34 \%$ first cousins once removed, and 5 or $0.21 \%$ second cousins. The total consanguinity rate was $1.22 \%$, and the mean inbreeding coefficient was 0.000557 , much lower than the values for the whole of Japan.
\end{abstract}

\section{INTRODUCTION}

Although the frequency of consanguineous marriages has been widely studied in Japan, data on largest cities, especially those in recent years, are rather meager. This communication presents data on consanguinity in parents of outpatients at the pediatric clinic of a hospital in Tokyo.

\section{MATERIALS AND METHODS}

During a period from July 1975 to July 1976, information on the relationship between parents of all outpatients was obtained as a part of the family history at the pediatric clinic in Musashino Red Cross Hospital, Musashino City, Tokyo. Accompanied adults, mostly parents, of the patients were asked whether the parents were related or not. If related, a further inquiry was made for more detailed information on the relationship, such that, the mother was a daughter of a brother of the father's mother, etc. Dates of births of the patients ranged from 1960 to 1976.

A majority of the patients came from the western, more recently urbanized districts (Musashino City, Mitaka City and others) of Metropolis Tokyo and a minority from $\mathrm{Ku}$-districts, which had been earlier urbanized. A few from outside of Tokyo were excluded from the subjects. Thus, 2,383 couples in total were available for the study.

Received April 18, 1978

${ }^{1}$ This study was supported by the Scientific Research Grant from the Ministry of Education, Science, and Culture of Japan No. 037020 in 1975 and No. 137071 in 1976 and 1977, and the Grant from the Ministry of Health and Welfare of Japan in 1974-1976 for the Research on Handicapped Children. 
Table 1. Frequency of consanguineous marriage among parents of outpatients at a

\begin{tabular}{|c|c|c|c|c|c|c|}
\hline \multirow{2}{*}{$\begin{array}{l}\text { Birth } \\
\text { year }\end{array}$} & \multicolumn{2}{|c|}{ Ku-districts } & \multicolumn{2}{|c|}{ Musashino City } & \multicolumn{2}{|c|}{ Mitaka City } \\
\hline & $\begin{array}{l}\text { No. of } \\
\text { couples }\end{array}$ & $\begin{array}{l}\text { Consan- } \\
\text { guinity }\end{array}$ & $\begin{array}{l}\text { No. of } \\
\text { couples }\end{array}$ & $\begin{array}{l}\text { Consan- } \\
\text { guinity }\end{array}$ & $\begin{array}{l}\text { No. of } \\
\text { couples }\end{array}$ & $\begin{array}{l}\text { Consan- } \\
\text { guinity }\end{array}$ \\
\hline 1960 & 1 & & 2 & & 1 & \\
\hline 1961 & 1 & & 12 & & 10 & \\
\hline 1962 & 3 & & 14 & & 11 & \\
\hline 1963 & 4 & & 6 & & 11 & (1C) \\
\hline 1964 & 1 & & 16 & & 19 & \\
\hline 1965 & 4 & & 20 & & 14 & \\
\hline 1966 & 1 & & 20 & & 23 & (1C) \\
\hline 1967 & 3 & & 13 & & 24 & \\
\hline 1968 & 4 & & 17 & & 27 & $(1.5 \mathrm{C})$ \\
\hline 1969 & 2 & & 25 & & 29 & \\
\hline 1970 & 8 & & 24 & (1C) & 48 & $(1 \mathrm{C}, 1.5 \mathrm{C})$ \\
\hline 1971 & 10 & & 46 & $(2 \mathrm{C})$ & 57 & $(2 \mathrm{C})$ \\
\hline 1972 & 7 & & 37 & & 40 & \\
\hline 1973 & 5 & & 50 & (1C) & 59 & $(1.5 \mathrm{C}, 1.5 \mathrm{C})$ \\
\hline 1974 & 23 & & 51 & & 62 & \\
\hline 1975 & 29 & & 126 & & 108 & $(1 \mathrm{C}, 1 \mathrm{C})$ \\
\hline 1976 & 8 & & 19 & & 25 & (1C) \\
\hline $\begin{array}{l}\text { Total } \\
(\%)\end{array}$ & 114 & 0 & 498 & $\begin{array}{c}3 \\
(0.60)\end{array}$ & 568 & $\begin{array}{c}11 \\
(1.94)\end{array}$ \\
\hline $1 \mathrm{C}$ & & & & 2 & & 6 \\
\hline$(\%)$ & & & & $(0.40)$ & & $(1.06)$ \\
\hline
\end{tabular}

$1 \mathrm{C}$ denotes a marriage between first cousins, $1.5 \mathrm{C}$ first cousins once removed, and $2 \mathrm{C}$ second

Since the patients who were immediately admitted to the hospital were not included, most of the recorded cases were rather slightly sick. Twenty nine patients born to consanguineous marriages were diagnosed as common cold (3), nasophalyngitis, parotitis, gastroenteritis, periodic vomiting (2), intestinal colic (2), abdominal pain, hyperthermia (2), fever of unknown etiology, febric convulsion (2), measles, tachycardia, proteinuria (2), eyelid edema, enuresis, angular stomatitis, staphylococcic dermatitis, umbilical polyp, congenital dislocation of hip joint, headache, clouding of consciousness (hysteria?) and no peculiarity. In none of these patients, signs of any autosomal recessive disorders were detected.

\section{RESULTS}

The materials were classified into four groups by the residence (Ku-district, Musashino City, Mitaka City, and other districts) and each group was subdivided by date of birth of the patients. Numbers of parent couples and those of related couples studied are shown in Table 1.

Of the 2,383 couples in total, 16 or $0.67 \%$ were first cousins, 8 or $0.34 \%$ first 
pediatric clinic by the birth year of the patients living in Metropolis Tokyo.

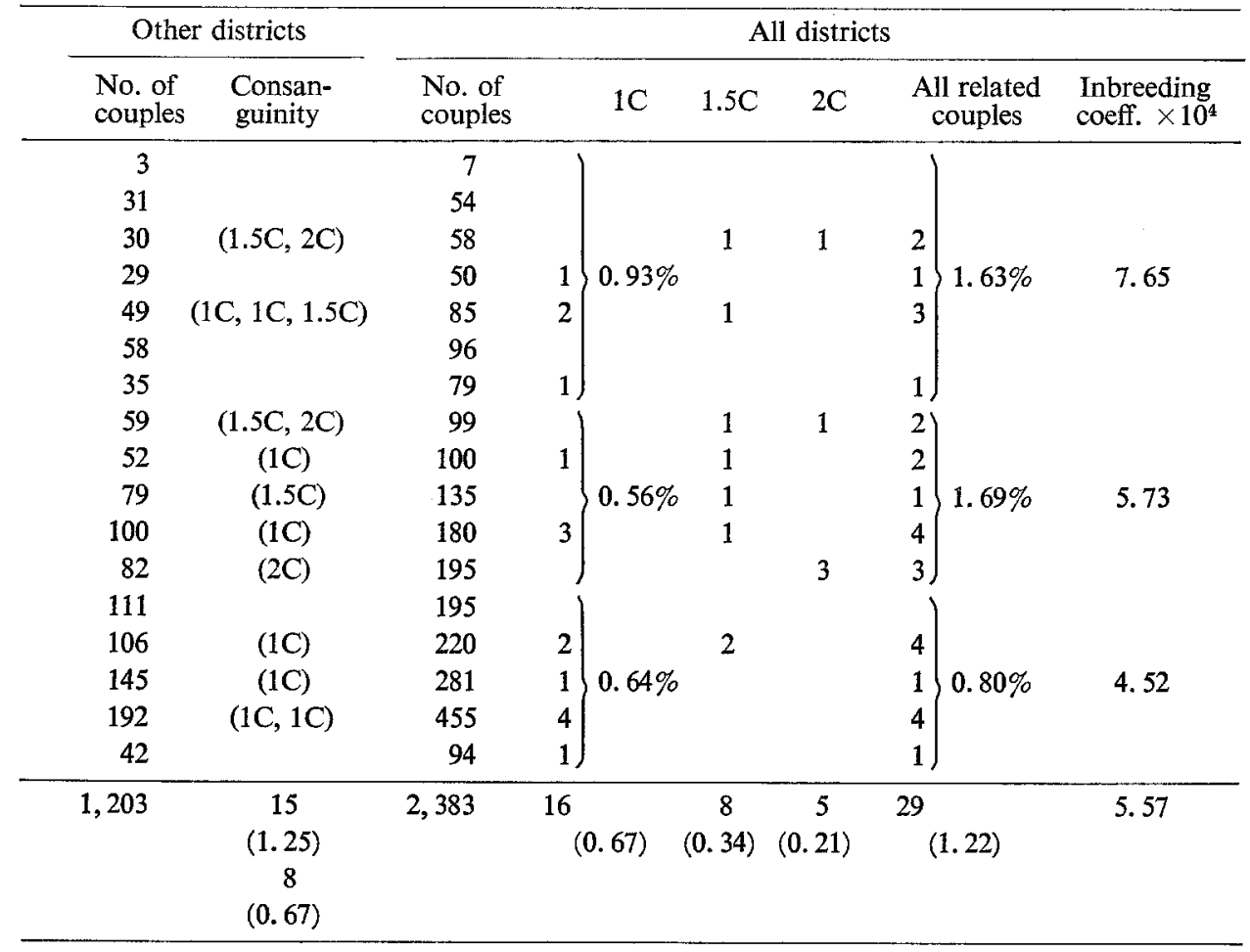

cousins.

cousins once removed, and 5 or $0.21 \%$ second cousins. Thus, 29 or $1.22 \%$ were related. The mean inbreeding coefficient was 0.000557 . No significant differences were noted in frequency of consanguineous marriages among the four districts. All the districts were pooled and the rate of consanguinity was compared among three classes, 1960-1966, 1967-1971, and 1972-1976 by date of birth of the patients. Though the rate of related marriages or first cousin marriages did not significantly differ among the classes, some indication of decline of the mean inbreeding coefficient may be suggested.

\section{DISCUSSION}

Prior to the War II, two studies were carried out on the incidence of consanguineous marriages in Tokyo. Kawakami (1931) recorded information on consanguinity of parents of 1,124 patients in an ophthalmologic clinic, of whom 74 patients with hereditary disorders were excluded. Of the remaining 1,050 couples, $4.0 \%$ were first cousins and the total inbreeding level was corresponded to $4.88 \%$ first cousins. That is, the mean inbreeding coefficient is estimated to be $0.0488 / 16$ 


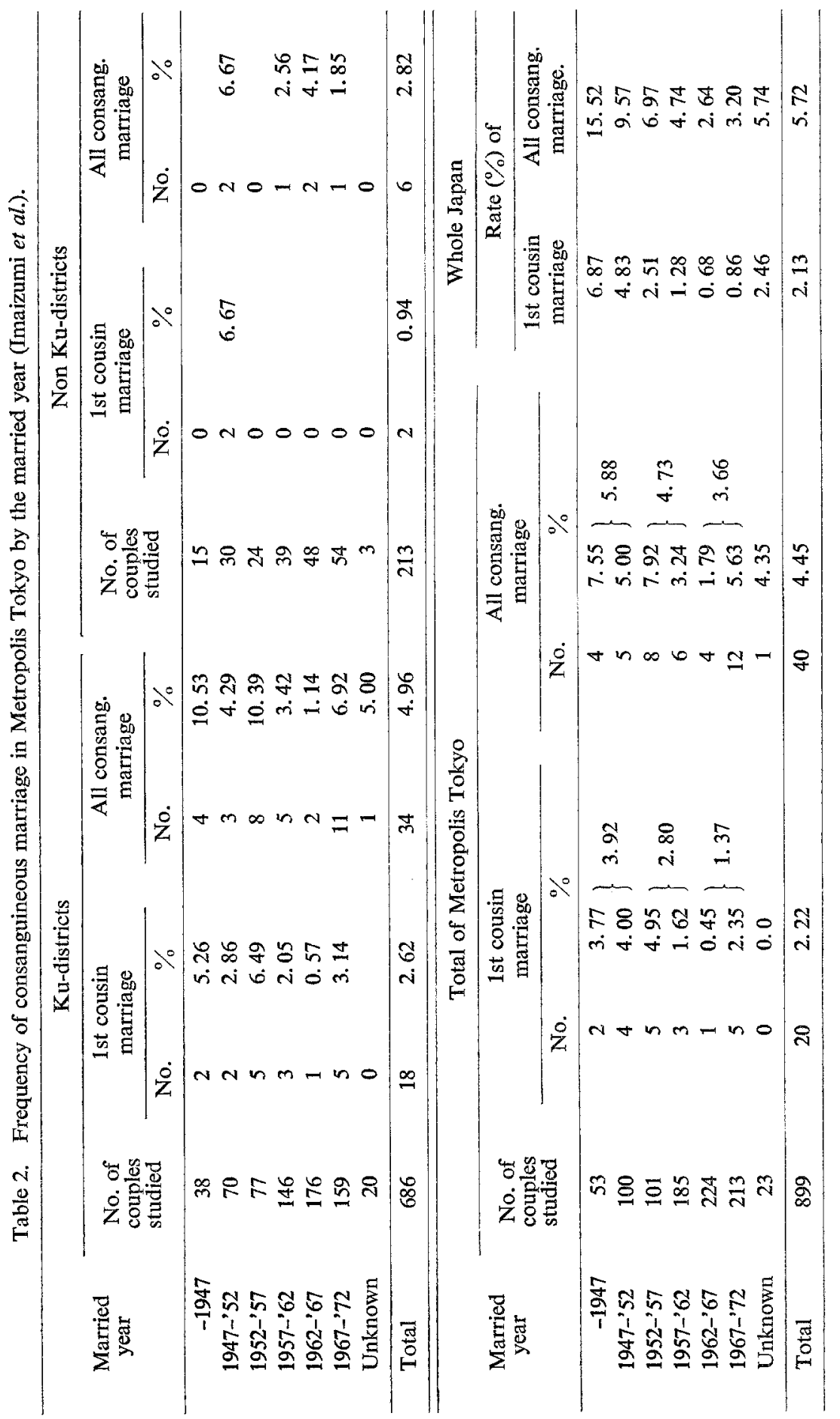


or 0.00305. Tachikawa and Kuwahara (1941) sent questionnaires to parents of all primary school children in Tokyo City, the area of which was identical to $\mathrm{Ku}$ district in the present Metropolis Tokyo. Of 363,797 questionnaire sheets recovered, 20,545 were reported to be related and 74,940 gave no information on consanguinity. Thus, the rate of consanguineous marriages was $5.65 \%$ of all the returned questionnaires and $7.11 \%$ of the effective answers.

After the War, in around 1955 Shinozaki (unpublished) carried out a study on consanguineous marriages in four populations in Tokyo. Incidences of all consanguineous marriages and first cousin marriages in two populations from $\mathrm{Ku}$-district (Shibuya-Ku and Chuo-Ku, pooled) were $7.90 \%$ and $4.67 \%$ respectively, and those in two populations from outside of $\mathrm{Ku}$ (Musashino City and Fuchu City, pooled) were $9.73 \%$ and $3.65 \%$ respectively.

In 1963, Furusho (unpublished) sent questionnaires to parents of all primary school children of the fifth year class, 10-11 years of age, in Suginami-Ku and obtained 4,151 effective answers.' By the use of these data, Komai (1972) estimated the mean inbreeding coefficient to be 0.0021 , which may approximately correspond to $2.5-2.7 \%$ first cousin marriage rate, provided that the contribution of first cousin marriage to the mean inbreeding coefficient for Japanese urban population was $75-80 \%$ as shown in the data of Shinozaki (unpublished) in Tokyo, Nakamoto (1969) in Fukuoka, and Komai and Tanaka (1972) in Shizuoka.

All these data seem to indicate that the frequency of consanguineous marriages in Tokyo remained considerably high among couples who married in 1950's or earlier. The present study, however, revealed that the mean inbreeding coefficient in recent Tokyo was as low as $18 \%$ of that in 1931 (Kawakami) and $26 \%$ of that in 1963 (Furusho).

More recently, Imaizumi et al. (1975) analyzed data of a nation-wide survey carried out using the questionnaire method by the Institute of Population Problem, Ministry of Health and Welfare, Japan, and pointed out that the frequency of consanguineous marriages in Japan had rapidly decreased from $16.25 \%$ among couples married on June 1, 1947 or earlier to $3.30 \%$ among those married during the period from June 2, 1967 to June 1, 1972.

By the courtesy of Imaizumi and others the present authors obtained their unpublished data on Tokyo, which indicate that the consanguinity rate was lower among couples married prior to 1952, and higher among those married after 1952 than that in the whole country (Table 2). Such inconsistency, however, may be ascribable to small size of the sample for Tokyo.

The present authors' data on the parents of patients born in 1960-1976 are compared with data of Imaizumi et al. (1975) from the whole country on couples married in 1957-1972. The consanguinity rate is lower in the former than that in the latter, the difference being insignificant in the rate of first cousin marriages $(0.67 \%$ vs. $0.93 \%)$, but highly significant at the $0.1 \%$ level in the rate of total con- 
sanguinity $(1.22 \%$ vs. $3.50 \%)$ as well as in the rate of marriages between first cousins, first cousins once removed and second cousins $(1.22 \%$ vs. $2.38 \%)$.

It should be pointed out that married people living in Tokyo may not necessarily have found their mate at Tokyo. The population of Tokyo has doubled during a period from 1947 to 1965 , mostly by immigration from all over the country. A considerable number of these immigrants, who had few acquaintances in Tokyo, tended to find mates at their native places, and had possibly increased the inbreeding level.

Acknowledgment The authors are greatly indebted to Drs. Y. Imaizumi, N. Shinozaki, H. Aoki and T. Furusho for their permission of the use of unpublished data. Peculiar thanks are due to Mrs. K. Haraoka and Mrs. Y. Shintaku for their cooperation in the study.

\section{REFERENCES}

Furusho, T. Unpublished, cited from Komai.

Imaizumi, Y., Shinozaki, N., and Aoki, H. 1975. Inbreeding in Japan: Results of a nation-wide study. Jap. J. Human Genet. 20: 91-107.

Imaizumi, Y., Shinozaki, N., and Aoki, H. Unpublished data.

Kawakami, R. 1931. Statistical consideration of consanguineous marriage (in Japanese). NipponIjishinpo No. 482.

Komai, T. 1972. Genetic studies on inbreeding in some Japanese populations. I. Introductory remarks. Jap. J. Human Genet. 17: 87-113.

Komai, T. and Tanaka, K. 1972. Genetic studies on inbreeding in some Japanese populations. II. The study of school children in Shizuoka: History, frequencies of consanguineous marriages and their subtypes, and comparability in socio-economic status among consanguinity classes. Jap. J. Human Genet. 17: 114-148.

Nakamoto, N. 1969. A study of consanguinity in Fukuoka, an urban population of large sizeMating patterns and degree of inbreeding (in Japanese). Fukuoka Acta Medica 60: 184-209.

Schull, W.J. and Neel, J.V. 1965. The Effects of Inbreeding on Japanese Children. Harper \& Row, New York.

Shinozaki, N. Unpublished, cited from Schull and Neel.

Tachikawa, K. and Kuwahara, R. 1941. Frequency of consanguineous marriages in Tokyo City (in Japanese). In: Quality and Life of Nation. Society of Population Problem Study, ed., TokoShoin, Tokyo, pp. 98-101. 